\title{
（153）。バナジウム触媒に関する研究（第了報） 三酸化バナジウムによる水素の吸着速度
}

多羅間公雄・寺西士一郎

前報1”のエチレンエェタンの吸着に用いたと同じ三酸化バナジ ウムに対する水素の吸着速度を測定した結果を報告する。

酸化バナジウムに対する水素の吸着については，Schwab, Taylor ${ }^{2)}$ 等仩り末発表実験值が示されているが, 吸着速度につ いては全く報告されていない。

\section{実 験 の 部}

I 試 料 三酸化バナジウム $\left(\mathrm{V}_{2} \mathrm{O}_{3}\right)$ は第 2 報に使用したもの で、これを $12.465 \mathrm{~g}$ 用いた。

水素は市販ボンベ入りのるのを常法により精彆乾燥して使用し た。

II 実确方法 吸着速度は恒圧, 静置沠でガス容積の減少速度 から求めた。実験は温度 $200,300,350^{\circ} \mathrm{C}$ に拀いて, 夫々水素压 力約 $200,300,400,500 \mathrm{mmHg}$ の条件で行つた。

\section{実験結果及び考察}

I 初期吸和速度式 測定された吸着速度曲線の一例を示すと 第 1 四の如くで, 水素吸着に持いて他の場合にもよく認められた 如く3), 初期には比較的速かな吸着か起るが，その吸着速度は急 に㜊くなり，飽和に達するかに見えるが，後に㖃慢な零次反応的 な吸着が知き中々飽和しない。この緩慢な吸着現象が如何なる原 因によつて起るかは明かでないが，我々はこれは表面に吸着され

第 1 図吸着速度曲楾

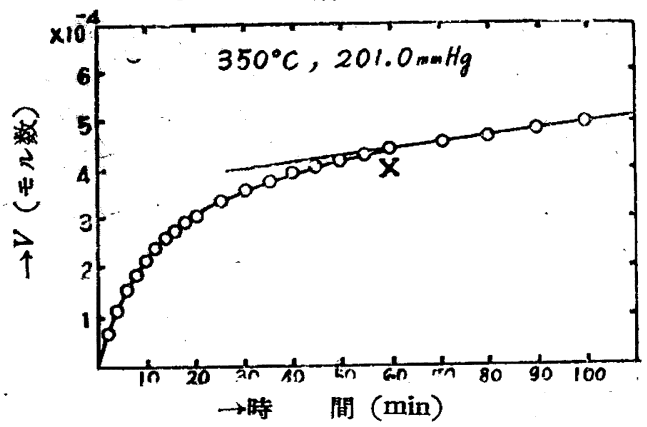

た水素が結晶内部に溶解するか, 或いは結晶表面のうち, 直接吸 着に関与しない部分へ表面移動するかのために観察される広義の 拡散現象であると仮定し，吸着速度曲線を初期と後期に分けて次 の如く解析した。

先ず初期段階においては, 吸着水素の脱着及び执散等の影響が 無視出来るから，その吸着速度式は普通の解離吸着の式

$$
\frac{1}{S} \cdot \frac{\mathrm{d} V_{S}}{\mathrm{~d} t}=k p\left(\frac{S-V S}{S}\right)^{2}
$$

1) 多篗間, その他, 工化 55,216(1952).

2) Schwab, Taylor, Spence, “Catalysis”, p. 209(1937).

3) 饭島, 物理化学 7,7(1933).
$V_{S}$ : 表面吸着量 $(\mathrm{M} / \mathrm{g}), \quad S$ : 吸着可能表面積を吸着量で表わし た值 $(\mathrm{M} / \mathrm{g}), \boldsymbol{p}$ : 水素圧力 $(\mathrm{mmHg}), k$ : 解離吸着速度恒数 $(1 / \mathrm{mm}$ Hg·min)で表わされ，これを積分すれば，

$$
-\frac{1}{V_{S}}=\frac{1}{S}+\frac{1}{k p S} \frac{1}{t}
$$

なる関係式を得る。

初期吸着の実験值を $1 / V_{S}$ と $1 / t$ の関係で図示すると第 2 図の 如くなり, 比輘的䛇差の多い最初の測定值を除けばいずれの温度 でも，初期段階に括いて (2) 式の関你が満され，又一定温度では 各直線が $1 / V S$ 軸上の一点で交わり一定の $S$ を与える。この $S$ と 压力 $p$ を用い直線の傾き， $1 / k p S$ より $k$ を算出すると第 1 表の如 く, 各温度で大体一定の值が得られる。

第 2 因

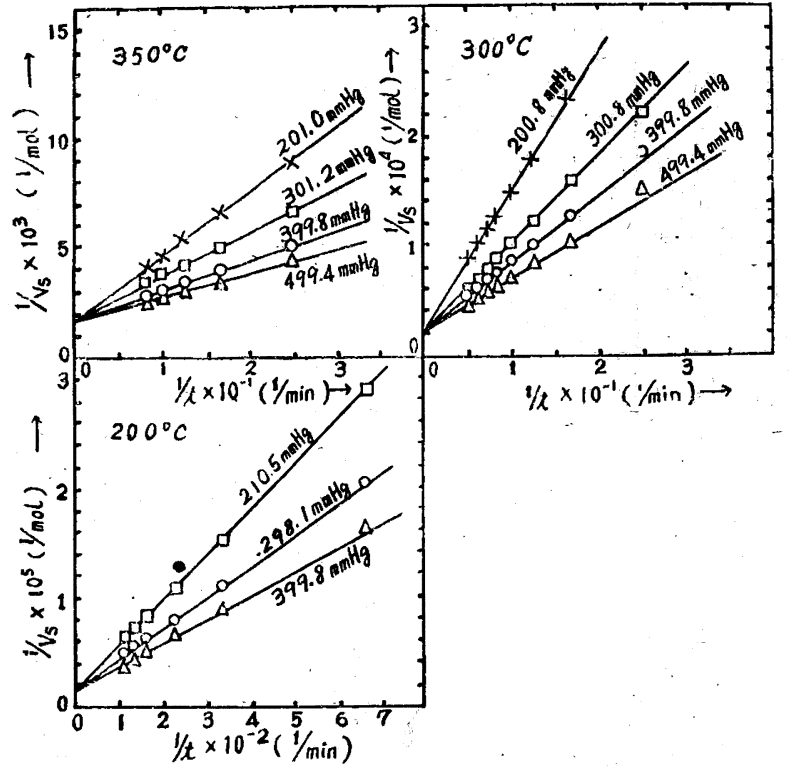

ここに得られた $S$ の值は, 温度が高い程僅か大となるが，これ は温度上昇に伴つて吸着に関与する吸着 site の数が堌すことを 意味し, 表面の不均一性に基因するるのと考えられるが，失験温 度範囲が，丁度吸着量が温度と共増大寸る点にあるためかとも 考えられる。

得られた $\boldsymbol{k}$ の温度变化から吸着活性化エネルギー $E_{k}$ を求める と $350 \sim 300^{\circ} \mathrm{C}$ では $16.1 \mathrm{kcal} / \mathrm{M}, 300 \sim 200^{\circ} \mathrm{C}$ では $8.36 \mathrm{kcal} / \mathrm{M}$ と著しく变化する。そこで上述の如く， $S$ が温度により影響を受 けることを考虑して, $k S$ の温度变化から吸着活性化ェネルギーを 求めると, この場合は $18.3 \mathrm{kcal} / \mathrm{M}$ なる一定值を得た。 


\begin{tabular}{|c|c|c|c|c|c|c|c|c|c|c|}
\hline \multirow[b]{2}{*}{ 温度 $\left({ }^{\circ} \mathrm{C}\right)$} & \multicolumn{2}{|r|}{ 第 } & \multicolumn{2}{|l|}{1} & \multicolumn{6}{|l|}{ 表 } \\
\hline & 王力 $(\mathrm{mmHg})$ & $S(\mathrm{M} / \mathrm{g})$ & \multicolumn{2}{|c|}{$V_{S s}(\mathrm{M} / \mathrm{g})$} & \multicolumn{2}{|c|}{$k(1 / \mathrm{mmHg} \cdot \mathrm{min})$} & \multicolumn{2}{|c|}{$r(1 / \min )$} & \multicolumn{2}{|c|}{$k^{\prime}(1 / \mathrm{min})$} \\
\hline 350 & 499.4 & $5.02 \times 10^{-5}$ & \multicolumn{2}{|c|}{$4.17 \times 10^{-5}$} & \multicolumn{2}{|c|}{$2.88 \times 10^{-4}$} & \multicolumn{2}{|c|}{$\left(2.87 \times 10^{-3}\right)$} & \multicolumn{2}{|c|}{$2.50 \times 10^{-3}$} \\
\hline " & 399.8 & '" & 3.93 & $"$ & 2.86 & $" 1$ & 5.55 & $" 1$ & 2.45 & $" 1$ \\
\hline " & 301.2 & $" \prime$ & 3.69 & " & 2.53 & " & 6.56 & " & 2.39 & " \\
\hline$"$ & 201.0 & $" \prime$ & 3.53 & " & 2.70 & $" \prime$ & 6.36 & $" \prime$ & 2.27 & $"$ \\
\hline$" 1$ & 平均值 & - & \multicolumn{2}{|c|}{ - } & \multicolumn{2}{|c|}{$2.74 \times 10^{-4}$} & \multicolumn{2}{|c|}{$6.16 \times 10^{-3}$} & \multicolumn{2}{|c|}{$2.40 \times 10^{-3}$} \\
\hline 300 & 499.4 & $3.65 \times 10^{-5}$ & \multicolumn{2}{|c|}{$2.96 \times 10^{-5}$} & \multicolumn{2}{|c|}{$8.97 \times 10^{-5}$} & \multicolumn{2}{|c|}{$4.56 \times 10^{-4}$} & \multicolumn{2}{|c|}{$1.63 \times 10^{-3}$} \\
\hline " & 399.8 & " & 2.90 & $"$ & 8.75 & $"$ & 4.58 & $" \prime$ & 1.49 & $" \prime$ \\
\hline " & 300.8 & $" \prime$ & 2.81 & " & 8.91 & " & 4.45 & $"$ & 1.50 & " \\
\hline " & 200.8 & $" 1$ & 2.65 & " & 8.62 & $" \prime$ & 4.64 & $" \prime$ & 1.47 & $" \prime$ \\
\hline$" \prime$ & 平均值 & - & \multicolumn{2}{|l|}{-} & \multicolumn{2}{|c|}{$8.81 \times 10^{-5}$} & \multicolumn{2}{|c|}{$4.56 \times 10^{-4}$} & \multicolumn{2}{|c|}{$1.52 \times 10^{-3}$} \\
\hline 200 & 399.8 & $5.02 \times 10^{-8}$ & \multicolumn{2}{|l|}{-} & \multicolumn{2}{|c|}{$1.78 \times 10^{-5}$} & \multicolumn{2}{|c|}{ - } & \multicolumn{2}{|c|}{-} \\
\hline "I & 298.1 & " & \multicolumn{2}{|l|}{ - } & 1.92 & $"$ & \multicolumn{2}{|l|}{ - } & \multicolumn{2}{|l|}{ - } \\
\hline " & 210.5 & $" \prime$ & \multicolumn{2}{|l|}{ - } & 1.85 & $" 1$ & \multicolumn{2}{|l|}{ - } & \multicolumn{2}{|l|}{ - } \\
\hline " & 平均値 & $-\quad-$ & \multicolumn{2}{|l|}{ - } & \multicolumn{2}{|c|}{$1.85 \times 10^{-5}$} & - & & - & \\
\hline
\end{tabular}

II 後期吸着速度式 拡散速度が表面吸着量に 1 次的に比例寸 るとすれば, 逆拡散が無視出来る範囲では

$$
\begin{aligned}
& \frac{\mathrm{d} V_{d}}{\mathrm{~d} t}=k^{\prime} V_{S} \\
& V_{d}: \text { 拡散に上る吸着量 }(\mathrm{M} / \mathrm{g}) \\
& k^{\prime}: \text { 拡散速度恒数 }(1 / \mathrm{min})
\end{aligned}
$$

なる関保が成立する。

さて後期の吸着速度曲線は，何れの場合も第 1 図の如くほぼ直 線的であり，この部分では表面吸着量は大体飽和値 $V S$ ～に達して いると考兄られるので，この直線の傾き即ち拡散速度から，次式

$$
\frac{\mathrm{d} V_{d}}{\mathrm{~d} t} \div k^{\prime} V_{S}
$$

によつて $k^{\prime} V$ s。が求められる。

又吸着速度曲線が (4) 式の直線にのり始め)る点(第 1 困の $\times$ 点) の吸着量は $V_{S e}$ と，それ迄に拡散によつて吸着した量との和に相 当するが，拡散吸着量は余り大きくないから，殆んどV $V_{S}$ に等し

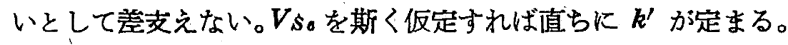
一方表面吸着速度式は (1) 式に脱着速度及び抬散速度を含めると

$$
\frac{\mathrm{d} V_{S}}{\mathrm{~d} t}=k p S\left(\frac{S-V_{S}}{S}\right)^{2}-r S\left(\frac{V_{S}}{S}\right)^{2}-k^{\prime} V_{S}
$$

$$
r: \text { 脱着速度恒数 }(1 / \mathrm{min})
$$

となるから，表面吸着の飽和状態では

$$
\frac{\mathrm{d} V S}{\mathrm{~d} t}=0
$$

- 即ち

$$
k p S\left(\frac{S-V_{S_{\theta}}}{S}\right)^{2}-r S\left(\frac{V S_{e}}{S}\right)^{2}-k^{\prime} V_{S_{\theta}}=0
$$

が成立する。この式に先に得た直䅫の傾き $\boldsymbol{k}^{\prime} V_{S 。}$ 及び上に仮定し たV $S_{e}$ とを代入すればてが求められる。この様にして得られた 及び $k^{\prime}$ の值を示すと夫々第 1 表の如く, 圧力の高い場合を除き， 大体一定温度では数\%以内の誤差で一定値か得られる。

脱着速度恒数 $r$ の温度变化から, 脱着活性化エネルギー $E_{k}$ を 求めると $E_{r}=36.9 \mathrm{kcal} / \mathrm{M}$ となり, これと先に得た $E_{\iota}(350 \sim$ $300^{\circ} \mathrm{C}$ の值) $16.1 \mathrm{kcal} / \mathrm{M}$ との差から表面吸着熱 $\Delta H_{a d}=-20.8$ $\mathrm{kcal} / \mathrm{M}$ を得る。又 $\boldsymbol{k}^{\prime}$ の温度变化から, 拡散活性エネルギー $\boldsymbol{E}_{k^{\prime}}$ として $6.46 \mathrm{kcal} / \mathrm{M}$ なる值を得る。これらの值はいずれも妥当な 值である4)
4）2）及び管，例豆，促媒 $4,28,44$ (1948) 等参照.

III 吸规速度曲線の計算 表面吸着速度式 (5) 及地散速度 式（3）を組合せて積分すると全吸着量 $V(M / B)$ は次式の如く時 閒の函数で表わさわる。

$$
\begin{aligned}
& V=S \cdot \phi(t)+\frac{b-2}{2 a}\left[\ln \left|a \phi(t)^{2}-b \phi(t)+1\right|\right. \\
& \left.+\frac{b}{\sqrt{ } \bar{q}}\left\{\ln \left|\frac{2 a \phi(t)-b-\sqrt{q}}{2 a \phi(t)-b+\sqrt{q}}\right|-\ln \left|\frac{b+\sqrt{q}}{b-\sqrt{q}}\right|\right\}\right] \\
& \text { ここに } \\
& \phi(t)=\frac{\left(2 k p+k^{\prime}-A\right) e^{A t+B}-\left(2 k p+k^{\prime}+A\right)}{2(k p-r)\left\{e^{A t+B}-1\right\}} \\
& A=\sqrt{4 k p\left(r+k^{\prime}\right)+k^{\prime 2}} ; B=\ln \left(\frac{2 k p+k^{\prime}+A}{2 k p+k^{\prime}-A}\right) \\
& a=\left(1-\frac{r}{k p}\right) ; b=\left(2+\frac{k^{\prime}}{k p}\right) ; q=b^{2}-4 a
\end{aligned}
$$

上に得た各過程の速度桓数 $k, r, k^{\prime}$ 夫々の平㘬值を，上式に代 入して求めた吸着速度曲線を $300^{\circ} \mathrm{C}$ の場合について示すと，第 3 园の実験で表わされた如くなり，500 $\mathrm{mmHg}$ の場合少しはずれる

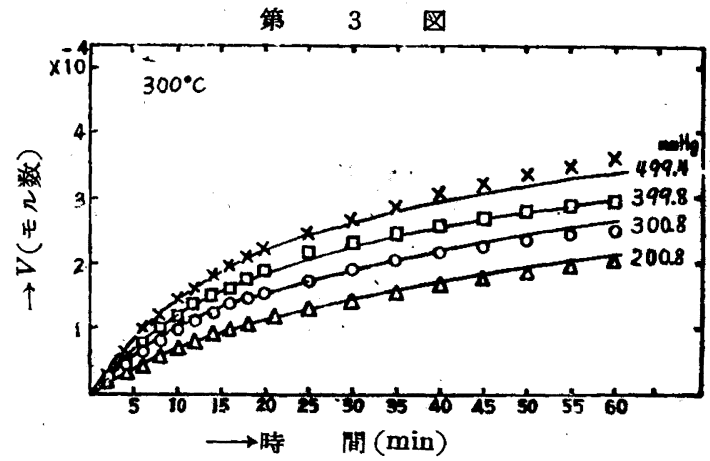

が, 他の場合は $k, r, k^{\prime}$ の誤差範囲内で央験値とかなり满足すへ き一致を示し, 上の速度式の妥当性を書書する。高圧力の条件で、 虽々不一致が認められるのは，吸着量が多く吸着原子間の相互作 用が無視出来なくなることも一つの原因であろう。

IV 理論喛散速度 前報です速べた如く $\mathrm{V}_{2} \mathrm{O}_{3}$ の結晶面の内, $(0,1, \overline{1})$ 面が主として吸着に関与していると考えられるか，この 面に於ける V-原子の配列状態は第 4 四の如くであり, 隣接 V原子対にはその距離が $2.78,2.93,3.37,3.82,4.16 \AA$ の 5 車か あり,この内 $2.78 \AA$ の対の間に，O-原子か平均 3 倜ずつ存在し

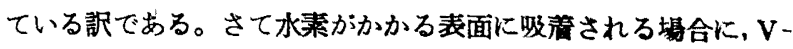
原子と Oー原子のいずれに吸着され易いかはこの実緰のみでは不 


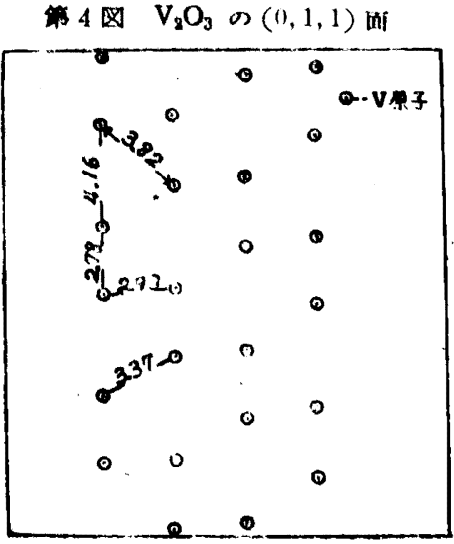

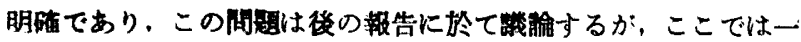

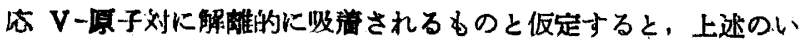

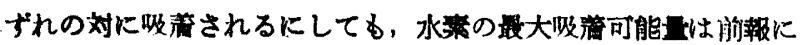

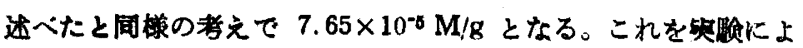
つて得た $S$ と比校するに $200^{\circ} \mathrm{C}$ の场合の值は小であるが, $300^{\circ} \mathrm{C}$ の $3.65 \times 10^{-t} \mathrm{M} / \mathrm{g}, 350^{\circ} \mathrm{C}$ の $5.02 \times 10^{-6} \mathrm{M} / \mathrm{g}$ なる值は妥当なも

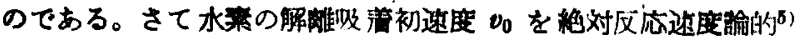

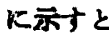

$$
\begin{gathered}
v_{0}=K \cdot \frac{k T}{h} \cdot \frac{n}{2} \cdot \frac{h^{3}}{(2 \pi m k T)^{0 / 2}} \\
\times \frac{h^{2}}{4 \pi^{2} I k T} \cdot C_{0} / R T \cdot C_{g} \cdot C_{d}
\end{gathered}
$$

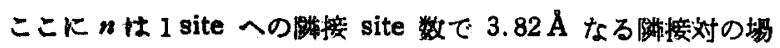
合2であるが，これ以外の烈接对の场合はすべて1であるからこ こでは $n=1$ とし， $K=1$ ，表面吸简可能 site 数。

$$
C,=2 \times 7.65 \times 10^{-8} \times 6.023 \times 10^{23} / \mathrm{g} \text {; }
$$

5) Eyring, Laidler, Glasstone, "The Theory of Rate

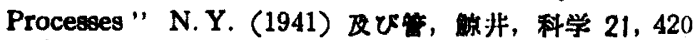
(1951).

$$
E_{0}=16,100+\frac{3}{2} R T_{m}\left(T_{m}=598^{\circ} \mathrm{K}\right)
$$

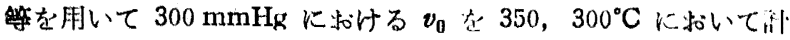

\begin{tabular}{|c|c|c|}
\hline 温度 $\left({ }^{\circ} \mathrm{C}\right)$ & 然测 做 & 旪筷溉 \\
\hline 350 & $6.37 \times 10^{-8}$ & $6.00 \times 10^{-t}$ \\
\hline$३ 00$ & $1.63 \times 10^{-8}$ & $2.11 \times 10^{-t}$ \\
\hline
\end{tabular}

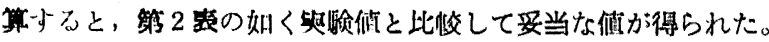

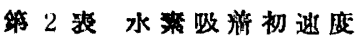

(vo $\mathrm{M} / \mathrm{g} \cdot \mathrm{sec} 300 \mathrm{mmHg}$ )

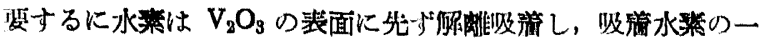

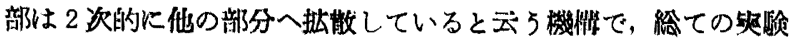
結果が满足に脱明比来た即である。

\section{括}

1) $\mathrm{V}_{2} \mathrm{O}_{3}$ に対する水慗の收萠逊度を温度 $200,300,350^{\circ} \mathrm{C}$, 压力 $200 \sim 500 \mathrm{mmHg}$ に於て测定した。

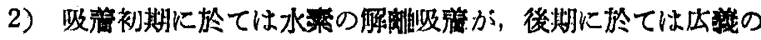

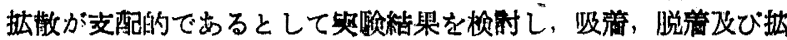

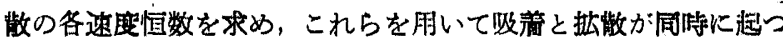

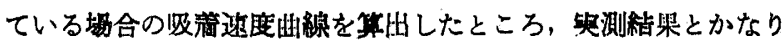
良く一敛した。

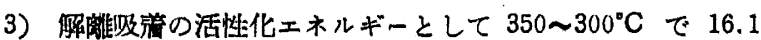

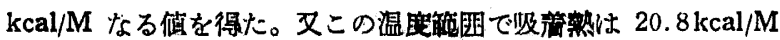

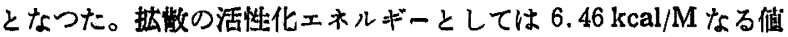
を得た。

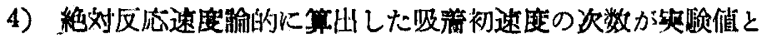
一致した。

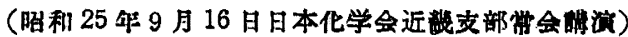

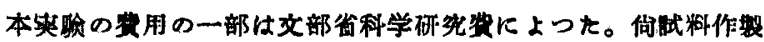

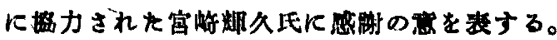

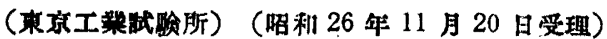

\title{
（154） $\mathrm{NH}_{3}-\mathrm{SO}_{3}$ 系無水反応に関する研究（第了報）
}

$$
\mathrm{NH}_{3}-\mathrm{SO}_{3} \text { 間の氣相反応 }
$$

\author{
內田傽五・伊藤幸夫
}

\section{1. 紼}

$\mathrm{NH}_{3}-\mathrm{SO}_{3}$ 阙の相反㑀については，従来反度条件を定めた組

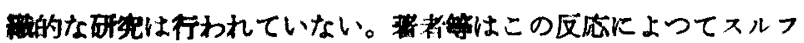

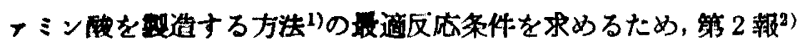
に抜告した分析方法を使用して， $\mathrm{NH}_{3}-\mathrm{SO}_{3}$ 阔の気相反纫を定量 的に梌村したのでその䊀果を報告する。

\section{2. 实唆の装显と方法}

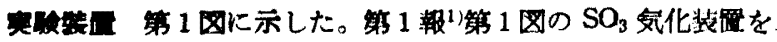

1）内田，伊管 工化 53,423(1950).

2) 内田，伊策 I化 54,256(1951).
因の如く改めて，更に定五肑に代給しらるように工夫した。通常 $\mathrm{SO}_{3}$ は固体であるが無水の㰡悲で一度これを蒸溜すれば， $20^{\circ} \mathrm{C}$ 以 上の富温では相当脚間淮体として取扱らことができる。

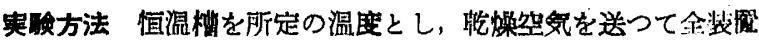

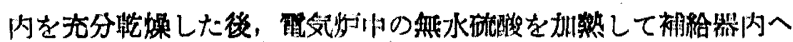

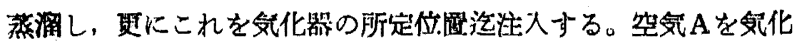
器へ迷り $\mathrm{SO}_{3}$ の溜出要が一定となる迄は $\mathrm{SO}_{3}$ 吸収管に通ずる。

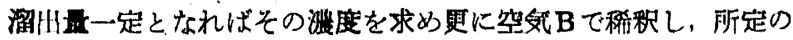

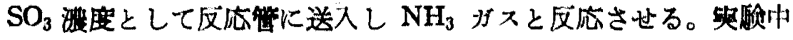

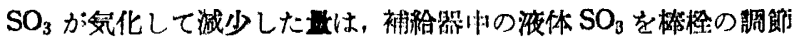
によつて紿えず補給する。 